\title{
Advanced Stirling Convertor (ASC) Technology Maturation
}

\author{
Wayne A. Wong ${ }^{1}$ and Scott Wilson ${ }^{2}$, \\ NASA Glenn Research Center, Cleveland, OH, 44135, USA \\ and \\ Josh Collins $^{3}$ and Kyle Wilson ${ }^{4}$ \\ Sunpower, Inc. Athens, OH, 45701, USA
}

\begin{abstract}
The Advanced Stirling Convertor (ASC) development effort was initiated by NASA Glenn Research Center (GRC) with contractor Sunpower Inc. to develop high efficiency thermal-to-electric power conversion technology for NASA Radioisotope Power Systems. Early successful performance demonstrations led to the expansion of the project as well as adoption of the technology by the Department of Energy (DOE) and system integration contractor Lockheed Martin Space Systems Company as part of the Advanced Stirling Radioisotope Generator (ASRG) flight project. The ASRG integrates a pair of ASCs to convert the heat from a pair of General Purpose Heat Source (GPHS) modules into electrical power. The expanded NASA ASC effort included development of several generations of ASC prototypes or Engineering Units to help prepare the ASC technology and Sunpower for flight implementation. Sunpower later had two parallel contracts allowing the last of the NASA Engineering Units called ASC-E3 to serve as pathfinders for the ASC-F flight convertors being built for DOE. The ASC-E3 convertors utilized the ASC-F flight specifications and were built using the ASC-F design and process documentation. Shortly after the first ASC-F Pair achieved initial operation, due to budget constraints, the DOE ASRG flight development contract was terminated. NASA continues to invest in the development of Stirling RPS technology including continued production of the ASC-E3 convertors, seven of which have been delivered with one additional unit in production. Starting in FY2015, Stirling Convertor Technology Maturation has been reorganized as an element of the RPS Stirling Cycle Technology Development (SCTD) Project and long-term plans for continued Stirling technology advancement are in reformulation. This paper provides a status on the ASC project, an overview of advancements made in the design and production of the ASC at Sunpower, and a summary of acceptance tests, reliability tests, and tactical tests at NASA GRC that demonstrate the capabilities of the ASC.
\end{abstract}

\section{Nomenclature}

$A S C=$ Advanced Stirling Convertor

$A S R G=$ Advanced Stirling Radioisotope Generator

GPHS = General Purpose Heat Source

RPS = Radioisotope Power System

\section{Introduction}

GOR decades, NASA has successfully used Radioisotope Power Systems (RPS) to enable some of the most significant space science discoveries, and the most ambitious of future missions that cannot be completed with solar power will require new high efficiency RPS. NASA Glenn Research Center (GRC) and Sunpower Inc. have been developing the 80 watt class Advanced Stirling Convertor (ASC) for such future applications. Sunpower's

\footnotetext{
${ }^{1}$ ASC Lead Engineering, Power Division, 21000 Brookpark Road, M.S. 301-2, Cleveland, OH, 44135.

${ }^{2}$ ASC Deputy Lead Engineer, Power Division, 21000 Brookpark Road, M.S. 301-2, Cleveland, OH, 44135.

${ }^{3}$ Project Manager, 1055 East State St, Suite D, Athens, OH.

${ }^{4}$ Engineering Manager, 1055 East State St, Suite D, Athens, OH.
} 
development of the ASC began as one of ten contracts within NASA GRC's Radioisotope Power Conversion Technology (RPCT) Project ${ }^{1}$ that included development of Stirling, thermoelectric, thermophotovoltaic, and Brayton technologies. By 2006, early ASC demonstration units established the high efficiency and potential for low mass and small size of the design. Based on these successes, NASA focused on expanding the development of the ASC. As the ASC technology advanced, efforts transitioned from the earlier technology demonstration and development phase to flight development as part of the Advanced Stirling Radioisotope Generator (ASRG) Integrated Federal Project. The ASRG Project was managed by the Department of Energy with system integration contractor Lockheed Martin Space Systems Company for NASA's Science Mission Directorate, Radioisotope Power System (RPS) Program. Sunpower had a subcontract to Lockheed Martin for ASC flight development and production and a parallel contract with GRC for engineering unit production. GRC had responsibility for engineering units as well as technical support to Lockheed Martin through a broad set of Government Furnished Service or "GFX" activities. The ASRG generator design, Figure 1, incorporates a pair of ASC convertors each of which is integrated to a General Purpose Heat Source (GPHS). The high heat-to-electric conversion efficiency of the ASC reduced the ASRG fuel requirements by a factor of 4 compared to thermoelectric systems, minimizing the use of the U.S.'s limited plutonium fuel inventory.

The ASC convertor design consists of a free-piston Stirling engine integrated with a linear alternator that utilizes technologies from Sunpower's cryocoolers, Sunpower's earlier 35 watt convertor developed under a NASA Small Business Innovative Research (SBIR) contract, along with advancements developed as part of the ASC that provide the required performance. The ASC incorporates hydrostatic gas bearings to allow non-contacting operation of the piston and displacer, high temperature heater head assembly utilizing nickel-based super-alloy, oxidation resistant high porosity regenerator, piston centering system, moving magnet alternator, displacer planar spring, and small clearances for the moving components. NASA and Sunpower's strategy to develop the ASC included several iterations of the design, each of which addressed objectives to advance the technology. Each progressive build includes design and processing updates to meet evolving requirements, enhance reliability, or improve manufacturability. The ASC-1 established $38 \%$ efficiency $\left(88 \mathrm{~W}_{\mathrm{AC}}\right.$ power output, $850^{\circ} \mathrm{C} \mathrm{T}_{\text {hot }}$ and $\left.90^{\circ} \mathrm{C} \mathrm{T}_{\text {cold }}\right) .^{2}$ The early ASC technology demonstrators, ASC-1, ASC-0, and ASC-1HS, continued to demonstrate high efficiency, small size, and low mass of the ASC design and included the development of weld joints, electrical feedthroughs, and process development needed for hermetic sealing of the convertors. The early successful convertor builds demonstrated the advantages of the ASC over other technologies being developed at the time and by 2006, NASA and DOE collaboratively agreed to transition the ASC from technology development to flight development. At that time, DOE and Lockheed Martin terminated efforts with a different Stirling convertor provider, and switched the generator design to use the Sunpower ASC convertors, naming the new generator configuration the ASRG. Figure 2 illustrates the ASC transition strategy, identifying the series of convertor builds and some of the advances made with each design. All of the convertors except for the ASC-F flight units were built by Sunpower under contract to NASA GRC.

To transition to flight, starting in 2006, three engineering unit ASC designs were envisioned to advance the technology's flight readiness level. The first of these, the ASC-E design was developed specifically to allow integration of a pair of convertors onto the first Stirling generator, the ASRG Engineering Unit (ASRG EU). Earlier ASC units were designed to be stand-alone laboratory demonstration units while, in contrast, the ASC-E had derived requirements from the ASRG EU including for the first time, structural, thermal, and electrical system interface definitions. While higher temperature capability up to $850^{\circ} \mathrm{C}$ was established with earlier ASC-1 and ASC-1HS, to allow earlier system demonstration, the ASRG EU design was based on a lower ASC hot end temperature of $650^{\circ} \mathrm{C}$ allowing the use of an IN718 heater head. In October 2007, Sunpower completed and GRC delivered to DOE, two ASC-E convertors plus a spare on schedule and that met performance requirements. ${ }^{3}$ DOE then provided the convertors to Lockheed Martin for integration on the ASRG EU which successfully completed a variety of system level demonstrations by Lockheed Martin. The ASRG EU was then transferred to GRC where it accumulated 33,000 hours

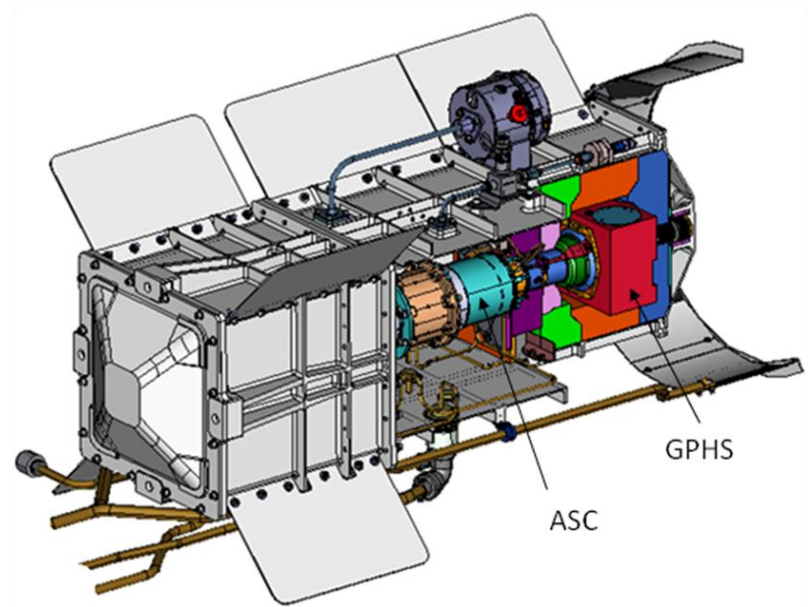

Figure 1. ASRG with two ASC convertors. 
of extended operation. ${ }^{4}$

Immediately after completion of the ASC-Es, the next ASC-E2 phase was initiated which was a step change in organization and design features based on anticipated reliability-driven and flight-driven requirements. A formal Quality Management System was instituted at Sunpower for the first time for the ASC-E2 build. The most significant design change was the heater head assembly which was completely redesigned to integrate the heat collector thermal and structural interface to the generator. The new heater head capable of maximum temperature operation of $850^{\circ} \mathrm{C}$ utilized 247LC nickel-based superalloy and required all-new production and processing development led by Refrac Systems, a new fabrication vendor for Sunpower. GRC continued to provide technical support including modeling and analysis, high temperature metallic characterization including coupon and head creep testing, organic materials tests and process optimization, vibration testing, reliability assessment, and continuous extended operation of the convertors. ${ }^{5}$ By 2010, Sunpower completed and delivered eight ASC-E2 convertors to GRC.

The remainder of this paper discusses the next phase of ASC development consisting of the ASC-F flight design and the parallel ASC-E3 engineering unit pathfinders. To date, including seven ASC-E3s, Sunpower has delivered 29 ASC convertors to GRC of varying pedigree and design as noted in Figure 2.

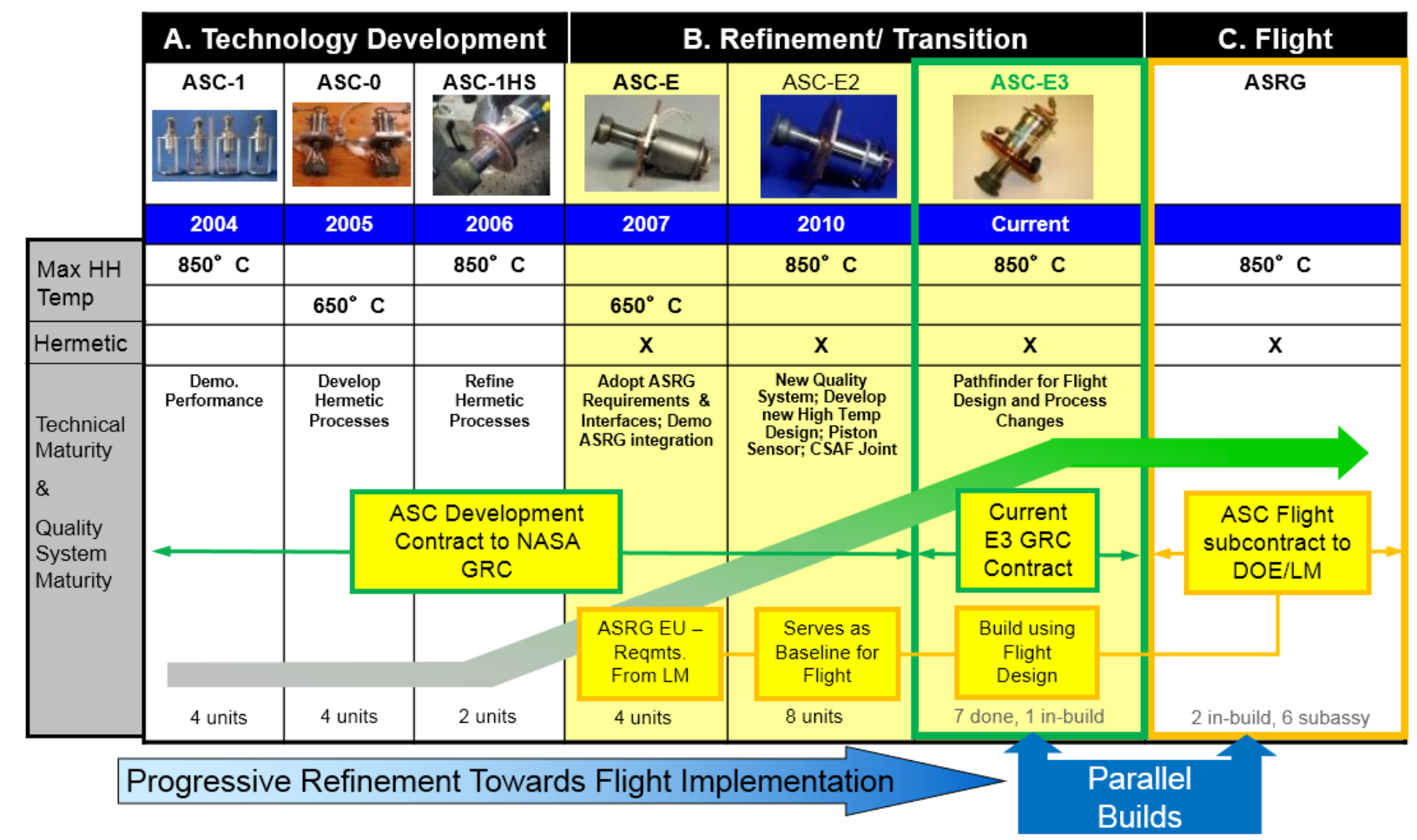

Figure 2. ASC Technology Evolution Strategy

\section{ASRG Integrated Flight Project}

With successful ASRG EU demonstrations and completed ASC-E2 convertor design to serve as a foundation, the ASC flight development was started as part of what eventually became the ASRG Integrated Federal Project. While all earlier ASC work by Sunpower was performed under contract to GRC, Sunpower entered a sub-contract to Lockheed Martin under the DOE ASRG Flight contract for ASC-F Flight Unit development. GRC reformulated the ASC-E3 development strategy to reflect the parallel contracts and concurrent ASC-F and ASC-E3 design and production efforts. Rather than sequential builds as illustrated in Figure 2, the ASC-E3 units were redefined as "flight-like" pathfinder convertors built to the same product specification and design as the ASC-F flight units. Eight ASC-F convertors and eight ASC-E3 convertors were planned. As some of the flight requirements, design, and production processes were still in development, the eight ASC-E3 convertors were sequenced to reduce risk to the flight convertors. The ASC-E3 Pair 1 convertors were the production pathfinders for the flight design but were 
not processed in a clean room. Prior to ASC-E3 Pair 2 initiation, Sunpower relocated to a new production facility which included a clean room specifically for flight ASC production. The ASC-E3 Pair 2 units were the first hardware to be produced in the clean room and served as production pathfinders ahead of the flight units. In order to serve as pathfinders, it was necessary to build the ASC-E3 Pair 1 and Pair 2 convertors significantly ahead of the flight units so that any lessons learned and corrective actions could be implemented for the flight builds. As a result, ASC-E3 Pair 1 and Pair 2 were built with the latest available ASC-F design documents and process requirements some of which were not finalized. Lessons learned from the early ASC-E3 pathfinders guided revisions and updates to the flight design. The ASC-E3 Pair 3 convertors were the production pathfinders using the approved ASC-F design and process documents. The ASC-E3 Pair 4 convertors were planned to be last in production giving priority to the eight ASC-F flight units.

The integrated ASRG project included two standing boards at the ASC element level to provide oversight and approval: the Joint ASC Configuration Control Board (CCB) that reviewed and approved design and production documents, and the ASC Material Review Board (MRB) that reviewed and approved non-conformances, corrective actions, and hardware disposition. Both Boards had representatives from Lockheed Martin, DOE, and GRC with Sunpower personnel typically presenting to the boards. Having joint boards was essential to ensure the ASC-E3 and ASC-F production was consistent and to maintain awareness of lessons learned and corrective actions from build to build.

\section{ASC Flight and Engineering Unit Production}

A more detailed accounting of accomplishments for the ASC-F flight unit and ASC-E3 engineering pathfinders is provided in Ref. 6 and 7 with emphasis on advancements made in the design, production capability, and quality management system. One of the significant improvements, driven by the need for clean room production, was relocating the company to a new facility with dedicated ASC test cells, lab space, production space, inspection area, and clean room. The facility was sized to allow for a maximum of four pairs of convertors operating at the same time in the four test cells, as shown in Figure 3. The ASC clean room in Figure 4 is an ISO Class 8 environment with ISO Class 5 laminar flow bench workspaces. Processing and development highlights include regenerator manufacturing and processing, and development of a new mechanical attachment joint for the cold side adapter flange (CSAF). Non-Destructive Evaluation (NDE) methods were also developed and implemented to ensure the heater head assembly, a critical component in the design, is

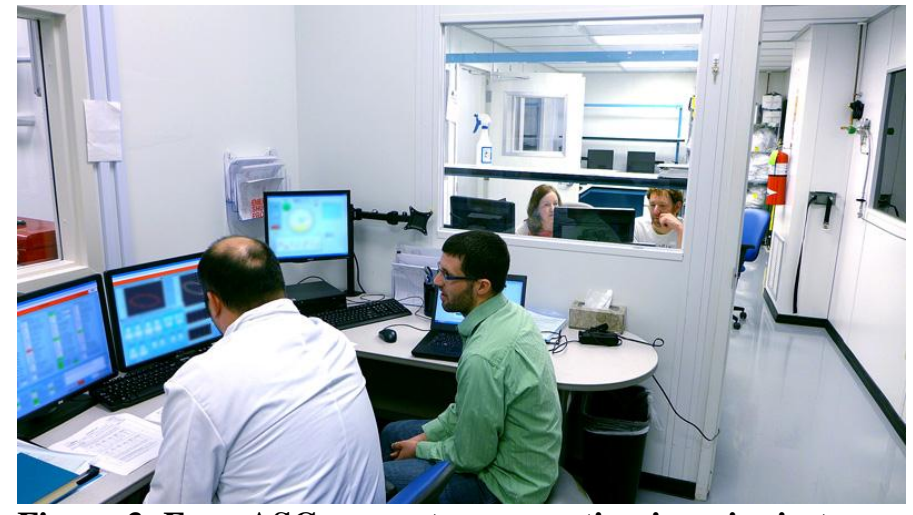

Figure 3. Four ASC convertors operating in pairs in two adjacent Sunpower test cells.

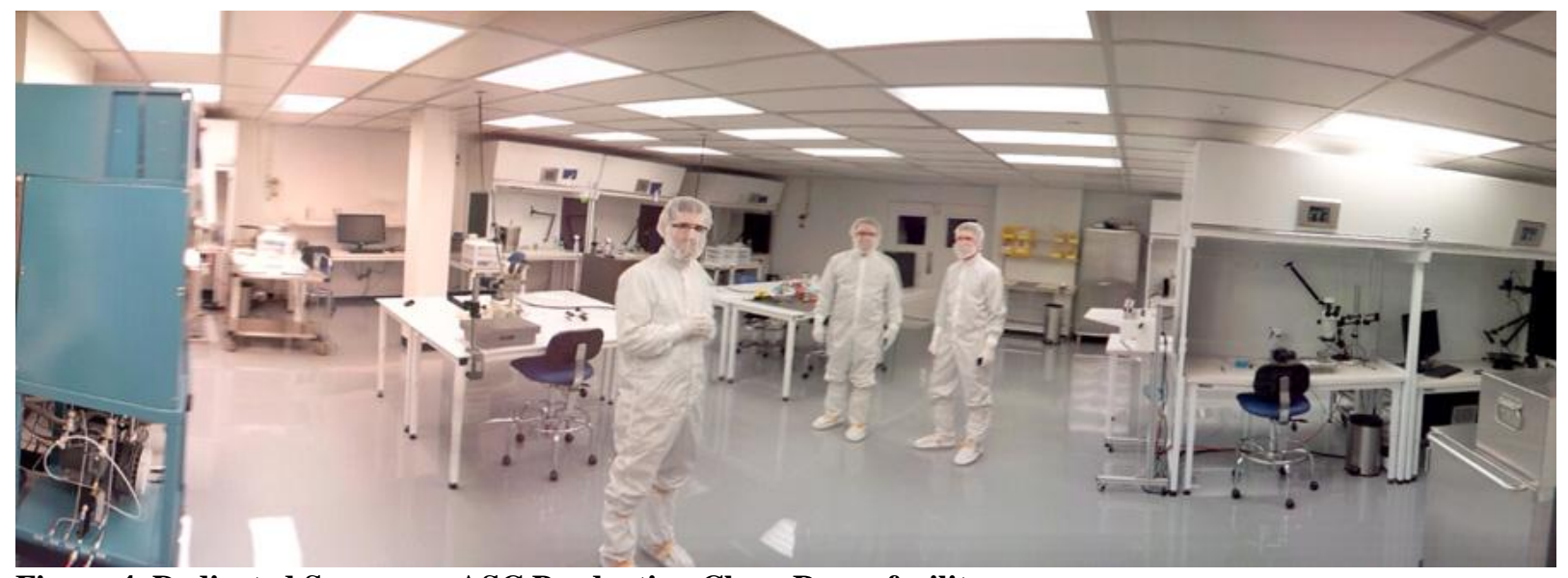

Figure 4. Dedicated Sunpower ASC Production Clean Room facility.

4

American Institute of Aeronautics and Astronautics 
screened to ensure conformance prior to integration onto a convertor. Other significant advancements are in testing capability: The use of the Common Performance Hardware (CPH) for all performance testing ensures consistent thermal input to minimize losses and data variability. The ASC-E3 convertors are installed in a $\mathrm{CPH}$, undergo final performance testing at Sunpower and are delivered to GRC installed in the same $\mathrm{CPH}$ to further reduce variability and processing time. A capability added to the Sunpower test stations that has improved processing is unattended operation. The controls and safeties used for unattended operation were developed over years of continuous extended operation testing across many different convertors at GRC. The GRC software controls as well as failsafe protection circuits were provided to Sunpower to allow Sunpower to operate in safe continuous unattended mode, and to also have further uniformity in testing

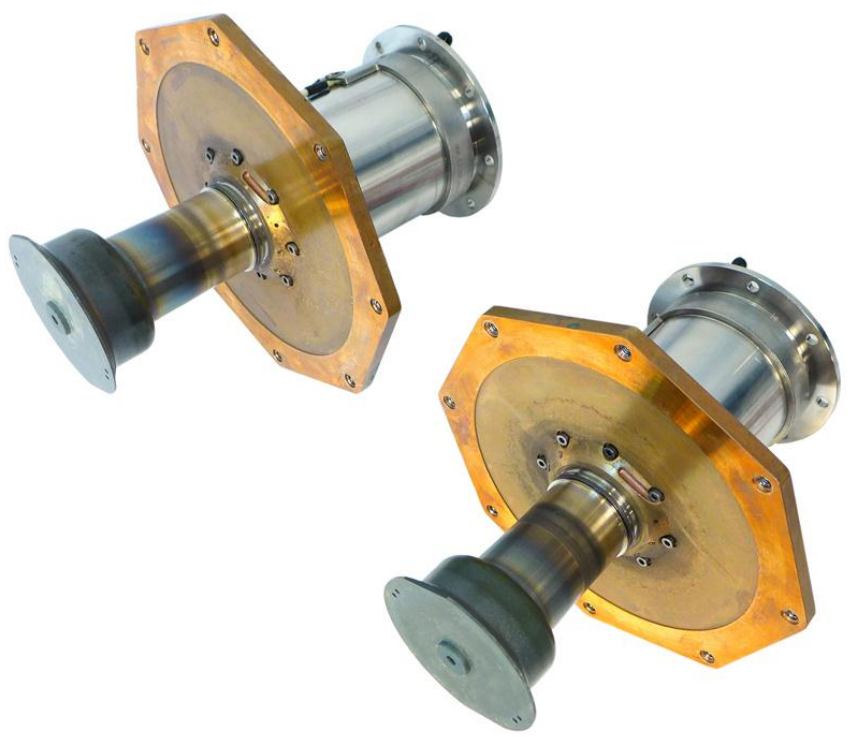

Figure 5. Completed Flight-like ASC-E3 Pair 3 Convertors between the two organizations. Lastly, Sunpower added the capability to easily rotate the convertor installed in its test setup to allow horizontal testing in four clocking orientations to evaluate lateral loading on the gas bearings in multiple configurations.

Much progress was made in completing the ASC-F flight design and assembling the first ASC-F Pair. Shortly after completing early operation of the ASC-F flight Pair 1, which was planned for integration in the ASRG Qualification Unit, the ASRG Project was cancelled primarily due to budgetary reasons. All flight assets have been transferred to the NASA GRC contract including:

1) ASC-F flight Pair 1 convertors secured in safe condition and stored in the clean room to preserve previous flight pedigree; all production paperwork also secured to preserve pedigree.

2) Complete assemblies intended for later ASC-F convertors as well as many components that were part of a shared common inventory to be used for the ASC-F and ASC-E3 builds.

3) All flight fixtures, tooling, test equipment, inspection, clean room and special processing equipment have transferred to enable use for ASC-E3 production.

\section{ASC-E3 Delivery and Acceptance Testing}

At the height of ASC production, Sunpower was processing and testing three pairs of convertors at once and by Fall 2013 had delivered the first two pairs of ASC-E3 to NASA, had ASC-E3 Pair 3 in production, and had initiated early operational testing of the first ASC-F flight pair. ASC-E3 Pair 1 provided initial verification that the flightlike design meets performance specifications. ASC-E3 Pair 1 was delivered to GRC in November 2012 where the convertors completed independent performance verification / acceptance testing. These units were later reconfigured in horizontal dual opposed configuration and then shipped to Lockheed Martin for controller testing. After they were returned to GRC, ASC-E3 Pair 1 convertors were integrated into the ASRG EU2 which successfully demonstrated the first operation of an electrically heated flight-like generator. After several hundred hours of operation, the ASRG EU2 experienced performance anomalies that are currently undergoing investigation. The ASC-E3 Pair 2 convertors were the first units to be built in the new dedicated Sunpower ASC Clean Room. ASCE3 \#4 was delivered in August 2013 and \#3 was delivered shortly afterwards in November 2013. These convertors have completed acceptance tests and continue in extended operation with \#4 leading at over 12,000 hours total GRC operation as of June 22, 2015. ASC-E3 Pair 3 convertors, shown in Figure 5, were delivered August 2014 and they have been operating consistently together both achieving over 5,700 hours. It is with Pair 3 that GRC began extended operation in horizontal configuration in four clockings. ASC-E3 \#8 is the latest convertor delivered to GRC in February 2015, see Figure 6. The convertor has passed acceptance activities and is undergoing detailed performance mapping. 
ASC-E3 \#7 halted production early in processing due to operational anomalies that were identified through testing at Sunpower. The anomaly investigation was managed through the MRB which eventually led to scrapping of the convertor in order to disassemble it and determine root cause. The investigation concluded that an installation nonconformance resulted in a gap when the regenerator and screen was not fully seated on the internal rejector. This caused some of the regenerator edge material to come loose, potentially due to vibrating material and screen during operation, and this debris eventually entered the compression space. The regenerator debris then compromised the gas bearing check valve operation resulting in the performance anomalies. The issue was exacerbated as the convertor was operated at newly required high piston amplitude "limits" test points that were beyond typical piston amplitude margin, that overstressed the regenerator material. Corrective actions were developed, approved by the MRB, and proven in trial hardware.

Production of ASC-E3 \#9 was intiated as a replacement for ASC-E3 \#7 and production adopted the corrective actions identified as a result of the scrapped convertor nonconformance. ASC-E3 \#9 is currently in early "shakedown" testing and the heater head weld and pressure vessel sleeve weld have been completed. ASC-E3 \#9 is anticipated to be delivered to GRC December 2015, upon which it will undergo the acceptance tests similar to previous ASC-E3 convertors and eventually enter extended operation. The delivered ASCE3 convertors are utilized at GRC to advance the technology and bolster the reliability

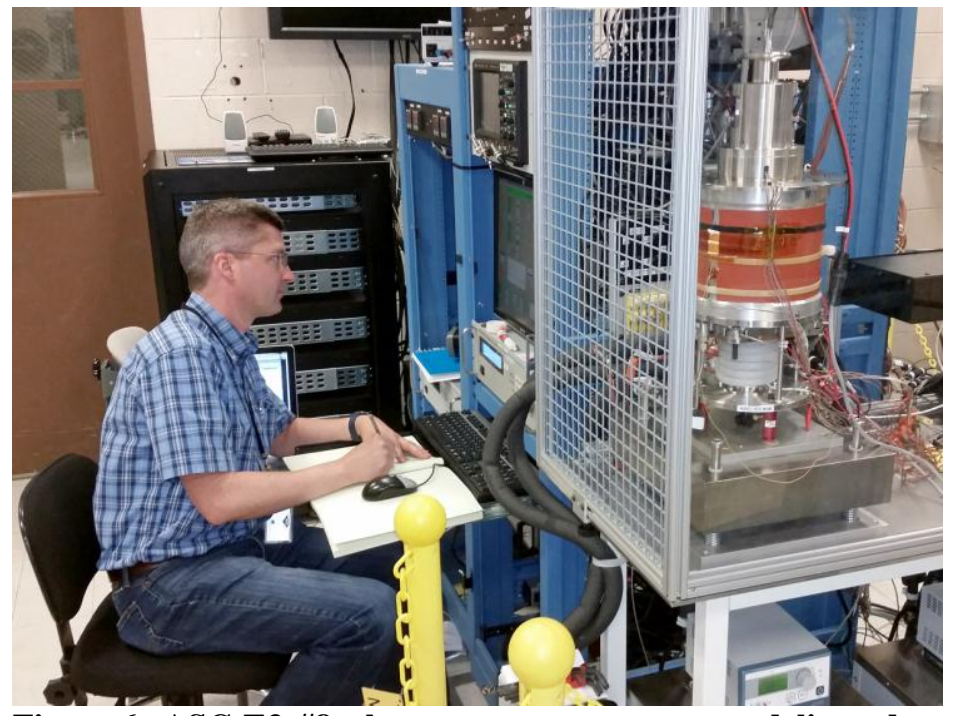

Figure 6. ASC-E3 \#8, the most recent convertor delivered to GRC, undergoing performance verification testing.

\section{ASC Operation and Key Demonstrations}

Upon Sunpower's delivery of ASC convertors to GRC's Stirling Research Laboratory (SRL), the units go through a series of inspection activity, installation and checkout in specially designed test stations, and then each convertor goes through acceptance tests which serve as independent performance verification that the units meet the ASC product specification to compare to Sunpower's equivalent pre-delivery final performance tests. The accuracy and repeatability of such tests and data comparisons is much improved for the ASC-E3 build due to the development of the "Common Performance Hardware" (consistent low heat loss insulation and electrical heater package that each convertor is delivered in) and "net heat input analysis" (used to compare performance to the specification heat input taking into account heat losses through the test system), which are discussed in Ref. 8 \& 9. Development of an ASC life certification plan is being considered dependent on path forward post-ASRG. The objective of such a plan is to identify activities needed to provide key data required for ASC life certification through reliability analyses focused on relevant environment testing and continuous extended testing of flight-like convertors such as the ASC-E3 units. Notionally, these convertors would undergo activities that approximate conditions and durations expected of a flight unit including pre-delivery testing, acceptance and characterization testing, simulated integration and fueled storage phases (horizontal operation), simulated dynamic environmental tests including flight acceptance and launch vibration simulation, followed by simulated flight mission phases. Figure 7 summarizes these activities and illustrates the progress made on the ASC-E3 convertors delivered to date. The total operating hours of each unit is segregated into the corresponding phases described. As shown, operation of ASC-E3 \#1 and \#2, which were integrated in the ASRG EU2, was halted due to performance anomalies observed during EU2 testing to allow investigation. Additionally, it should be noted that for ASC-E3 \#5 and \#6, Phase 3 testing is split into several yellow cells, each cell representing one of the four planned horizontal clocking configurations - they are currently in the third horizontal configuration. 


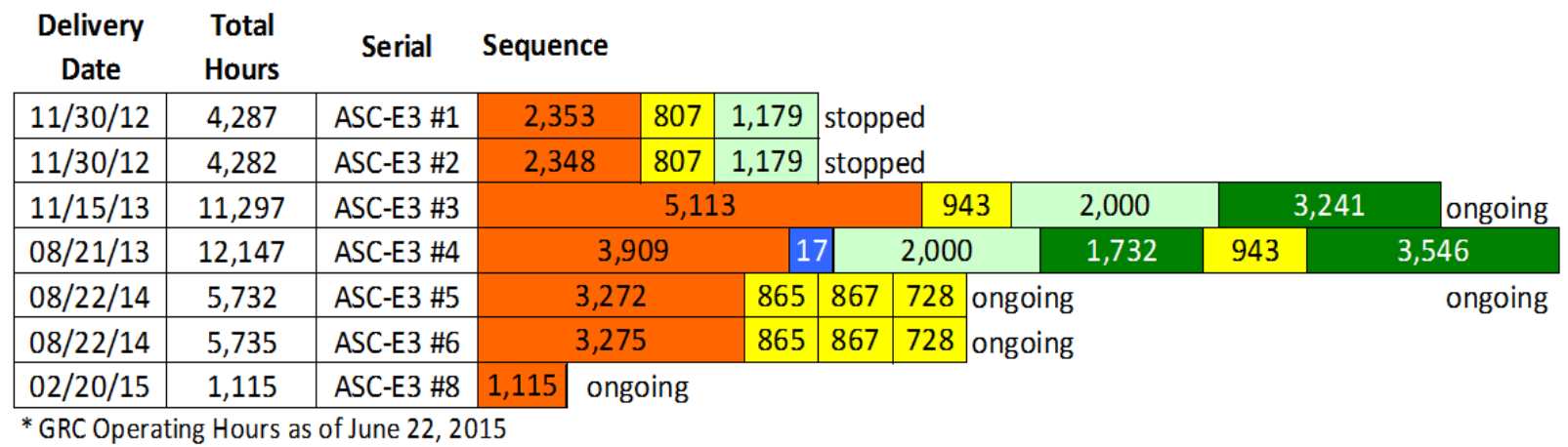

\begin{tabular}{|c|c|c|c|c|c|c|}
\hline Test Seq. & 1 & 2 & 3 & 4 & 5 & 6 \\
\hline Description & $\begin{array}{c}\text { Pre-delivery: Hardware } \\
\text { Acceptance Rev., Transport } \\
\text { to GRC }\end{array}$ & $\begin{array}{c}\text { Characterization, } \\
\text { Independent Performance } \\
\text { Verification }\end{array}$ & $\begin{array}{l}\text { Simulated Integration \& } \\
\text { Storage (horizontal) }\end{array}$ & \begin{tabular}{|c|} 
Simulated Dynamic \\
Environment, including Flight \\
Accept. \& Launch Sim. \\
\end{tabular} & Early-Life Phase & Simulated Cruise \\
\hline $\begin{array}{l}\text { Configuration, } \\
\text { Orientation }\end{array}$ & $\begin{array}{c}\text { Delivered in Common } \\
\text { Performance Hardware } \\
\text { (CPH), single vertical }\end{array}$ & $\mathrm{CPH}$, single vertical & $\begin{array}{c}\mathrm{CPH}, \text { single or dual-opposed } \\
\text { horizontal }\end{array}$ & Single horizontal & $\begin{array}{c}\text { Single or dual- } \\
\text { opposed vertical }\end{array}$ & $\begin{array}{l}\text { Single or dual- } \\
\text { opposed vertical }\end{array}$ \\
\hline Duration & $\begin{array}{c}\text { No limit on production hours, } \\
\text { delivered with } 400 \text { to } 1,000 \\
\text { hrs }\end{array}$ & No limit, $\sim 2,000 \mathrm{hrs}$ & Specified, $800-1,000 \mathrm{hrs}$, & No limit, $\sim 10 \mathrm{hrs}$, & TBD & $\mathrm{TBD}$ \\
\hline
\end{tabular}

Figure 7. Summary of operation of the ASC-E3 flight pathfinder convertors.

\section{A. Environmental Testing - Random Vibration Exposure}

To demonstrate a high Technology Readiness Level, key activities include successful demonstrations in relevant environments. For the ASC, testing that simulated relevant environments include dynamic loading from random vibration exposure in three axes, static loads from constant acceleration tests, thermal exposure to operating conditions, and operational orientation tests. The GRC Structural Dynamics Laboratory has been used to perform vibration exposure tests on multiple ASC convertors of varying builds at random vibration levels defined in the ASC specification. All ASC-E, ASC-E2 and the first four ASC-E3 convertors have gone through lower workmanshiplevel vibration testing as part of production activities prior to delivery. Based on success of convertor workmanship vibration testing and lack of any anomalous findings in any of the many previous workmanship-level vibration exposures, and also as a cost and schedule savings, the workmanship vibration requirement was removed for later ASC-E3 convertors. Additionally, as part of the notional life certification activity, each convertor undergoes flight acceptance and launch-level random vibration environmental testing in three axes. Short term success includes comparison of pre-vibe and post-vibe operational test data to determine no change in performance or characteristics. The vibration testing is followed by extended operations to verify long term operational success after exposure.

Of the ASC-E3 convertors, unit \#4 has undergone flight acceptance and launch level vibration exposures, as shown in Figure 8. The convertor successfully passed the vibe test which was conducted when it had 2,214 hours of operation and that unit has now accumulated a total of 12,147 hours at GRC. It has continued to operate for nearly 10,000 hours after exposure to the environmental test without issue. Dependent on funding priorities, similar flight acceptance and launch-level vibration exposure testing is planned for each of the flight-like ASC-E3 Pair 3 and Pair 4 units. Additionally, higher qualification-level vibration testing has been successfully completed on an upgraded ASC-E2 \#2. The ASC-E2 \#2 was rebuilt to be more ASC-E3-like as it incorporates flight and ASC-E3 design changes including upgraded geometries, clearances and linear alternator.

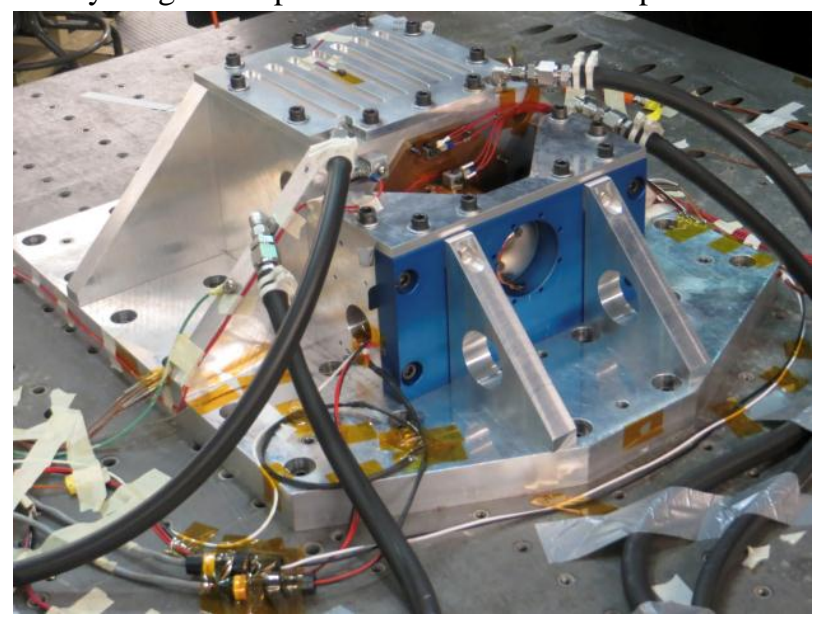

Figure 8. ASC installed in the GRC Structural Dynamics Laboratory for random vibration testing. 


\section{B. Constant Acceleration Load Test}

While the upgraded ASC-E2 \#2 has similar form, fit, and function as the flight and ASC-E3 design, the convertor is a tactical unit used for specific shorter term tests as oppose to the continuous extended operation of most of the ASC-E3 convertors. In addition to vibe testing, the upgraded ASC-E2 \#2 was also used for static g-load exposure on a centrifuge in both the axial and lateral directions. The static g-loading is specified in the ASC product specification and represents loads expected from the Star48 Rocket, and landing loads. The test was conducted using a centrifuge (Figure 9) located at the Case Western Reserve University (CWRU) and due to slow spin-up and spin-down to the desired g-levels, the tests represent an over-exposure of $5 \mathrm{x}$ duration for the Star48 profile, and $7 \mathrm{x}$ duration on the landing profile. The ASC-E2 \#2 passed the test based on comparison of pre-spin vs post-spin operational data and characteristics, as well as disassembly of the convertor to inspect the running surfaces which indicated no observed degradation and no debris generation.

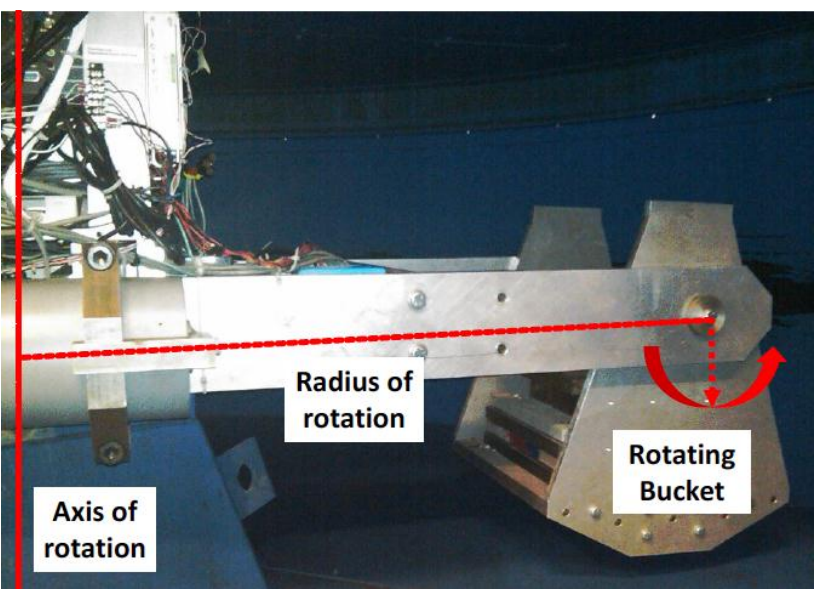

Figure 9. ASC installed in the test bucket of the CWRU Centrifuge for static load testing.

\section{Thermal Exposure and Operational Orientation}

Two additional environments are thermal exposure and operational orientation. For the ASC, the thermal conditions are prescribed by the ASC specification which includes various mission conditions and additional conditions that represent margin, such as Beginning of Life (BOL), End of Life (EOL), high reject (HR), low reject (LR), and Maximum Qualification, and Minimum Qualification temperatures. The convertors are operated at these conditions numerous times throughout production at Sunpower and are further operated at these conditions during testing at GRC. No issues have been identified on any of the convertors related to thermal exposure.

Operational orientation is considered to account for longer time periods during integration, transportation, and fueled storage of a flight unit when the convertors are in a horizontal orientation. When the convertors are horizontal, gravity provides a lateral load against the gas bearing surfaces. Previously, horizontal testing at Sunpower was at only one horizontal position. Current ASC-E3 production requires each convertor to undergo horizontal testing in 4-clocking orientations to ensure proper gas bearing function against 1-g lateral load at the prescribed operating temperature ranges. All delivered ASC-E3 convertors passed their respective horizontal tests during production. Further, ASC-E3 convertors undergo extended testing in horizontal orientation at GRC after delivery. The horizontal durations are derived from conservative estimates on horizontal processing of flight units. ASC-E3 Pair 1 and Pair 2 underwent extended horizontal testing in one position at GRC. Starting with ASC-E3 Pair 3 , testing includes extended operation at each of the four clocking orientations. Pair 3 is currently in the third clocking position. To date, no issues have been identified related to extended horizontal testing.

\section{Gas Bearings and Xylan Coated Running Surfaces}

The ASC design incorporates a gas bearing system and Xylan coatings on the piston and displacer running surfaces. The complementary gas bearing system and Xylan coatings are used on all Sunpower Stirling free-piston machines including flight cryocoolers, 52 of which have been used in space applications as of May 2015. In the ASC design, for the vast majority of operation, the gas bearings ensure non-contact operation of the moving parts to avoid wear. ASC production includes vertical and horizontal testing at a range of conditions including temperature extremes as well as piston amplitude extremes that are beyond typical operatin conditions expected in flight. Careful inspection of the running surfaces after such tests require the absence of rubs, indicating non-contact during the range of exposed conditions, verifying proper gas bearing function and adequate running clearances. For expected short durations when radial contact of the piston and displacer bearing surfaces are possible, Xylan, a low friction wear resistant coating prevents damage to the moving parts. Such contact is anticipated during brief start-up and shut-down periods while the gas bearing system is reaching sufficiently high pressure. Additionally, lateral contact is possible during static g-loads and also during high-level random vibration exposures. As discussed above, the vibration testing at launch and higher qualification levels and the static g-load testing with longer duration exposures have successfully demonstrated that the combination of gas bearings and Xylan prevents damage and debris generation for these extreme specified conditions. Additionally, ASC-E2 \#8 was used for start/stop durability 
testing with the goal of demonstrating margin by starting and stopping the unit a total of 301 cycles (201 vertical, plus 100 horizontal), which is at least double the cycles anticipated for a flight unit. The result of the successful start/stop durability test is that no change in running surfaces was detected other than an anticipated light buffing, and that no evidence of debris was found.

\section{ASC Design Improvement and Technology Assessment}

As NASA reformulates plans for Stirling RPS development post-ASRG, the ASC and associated technologies are being assessed for opportunities to improve the design. In the course of ASC-E2 and ASC-E3 experiences, both in terms of Sunpower production and GRC operations of the delivered units, there have been valuable lessons learned. Some of these lessons were only possible through extended testing and evaluation. The objectives of any potential design changes are to increase robustness and reliability, address areas of uncertainty, and potentially evaluate production manufacturing/parts choices. Any design improvements are not for the purpose of improving convertor performance as the ASC is already a very efficient design. In fact, for the design updates, when necessary, reasonable reduction in performance for the benefit of robustness will be considered acceptable. Sunpower is conducting the ASC technology assessment this summer and identification of a number of promising design options are anticipated.

\section{Status and Path Forward}

In late Fall 2013, DOE initiated termination of the Lockheed Martin ASRG flight development contract, driven largely by budget constraints. As a consequence, all work on the ASC-F flight convertors was stopped as Sunpower's subcontract to Lockheed Martin also initiated termination. At the time of termination, the ASC-F design was complete and NASA's contract with Sunpower to produce the ASC-E3s based on the flight design continued. NASA continues to recognize the importance of high efficiency Stirling power conversion for RPS and continues investment in the technology. The Stirling RPS development activity is being reformulated and the Stirling convertor technology maturation element is part of the new Stirling Cycle Technology Development (SCTD) Project at GRC. Initial activities as a result of termination were reported previously ${ }^{6}$ including transfer of all flight ASC assets from the DOE contract to the NASA contract, re-planning of the ASC-E3 builds to accelerate ASC-E3 Pair 4, prioritizing the integration of ASRG EU2 using ASC-E3 Pair 1, and the award of a NASA GRC contract to Lockheed Martin to complete production and delivery of the EDU4 controller.

Currently, Sunpower is continuing production of ASC-E3 \#9 with an anticipated delivery at the end of 2015. Meanwhile, Sunpower is conducting an ASC design improvement and technology assessment that will provide input to NASA on options for increasing the robustness of the ASC technology. As limited availability of plutonium-238 fuel continues to be a driver for NASA science mission planning, high efficiency Stirling technology remains crucial for future NASA RPS.

\section{Acknowledgement}

The work described in this paper was performed for the Science Mission Directorate (SMD) and the Radioisotope Power System (RPS) Program. The opinions expressed in this paper are those of the authors and do not necessarily reflect the views of the National Aeronautics and Space Administration. The authors thank the ASC and ASRG integrated team for the many significant contributions to advancing Stirling RPS technology.

\section{References}

${ }^{1}$ Wong, W. A., Anderson, D. J., and Tuttle, K. L., "Status of NASA's Advanced Radioisotope Power Conversion Technology Research and Development," in the Proceedings for Space Technology and Applications International Forum (STAIF-2006), Albuquerque, NM, 2006 and also published as NASA TM-2006-214243.

${ }^{2}$ Wood, J. G., Wilson, K., et al., "Continuing Development of the Advanced Stirling Convertor (ASC)," Fifth International Energy Conversion Engineering Conference (IECEC-2007), Cleveland, OH, 2007, AIAA and also published as NASA TM2008-215021. 
${ }^{3}$ Wong, W. A., Wood, L. G, and Wilson, K., “Advanced Stirling Convertor (ASC) - From Technology Development to Future Flight Product," in the Proceedings for Space Technology and Applications International Forum (STAIF-2008), Albuquerque, NM, 2008 and also published as NASA TM-2008-215282.

${ }^{4}$ Lewandowski, E. J., "Testing of the Advanced Stirling Radioisotope Generator Engineering Unit at NASA Glenn Research Center," Tenth International Energy Conversion Engineering Conference (IECEC-2012), Atlanta, GA, 2012, AIAA.

${ }^{5}$ Schreiber, J. G., Thieme, L. G., and Wong, W. A., "Supporting Technology at GRC to Mitigate Risk as Stirling Power Conversion Transitions to Flight," Sixth International Energy Conversion Engineering Conference (IECEC-2008), Cleveland, OH, 2008, AIAA and also published as NASA TM-2009-215515.

${ }^{6}$ Collins, J., Wong, W. A., Dunlap, M. A., Smith, E., Wilson, K., "Sunpower's Dynamic Conversion to Flight with the Advanced Stirling Convertor (ASC-F)," Tenth International Energy Conversion Engineering Conference (IECEC-2012), Atlanta, GA, 2012, AIAA.

${ }^{7}$ Wong, W. A., Wilson, S. D., and Collins, J., “Advanced Stirling Convertor (ASC) Development for NASA RPS” Twelfth International Energy Conversion Engineering Conference (IECEC-2014), Cleveland, OH 2014, AIAA.

${ }^{8}$ Wilson, S. D., Wong, W. A., "NASA Glenn Research Center Support of the ASRG," Twelfth International Energy Conversion Engineering Conference (IECEC-2014), Cleveland, OH 2014, AIAA.

${ }^{9}$ Wilson, S. D., Reid, T. V., Schifer, N. A., and Briggs, M., "Overview of Heat Addition and Efficiency Predictions for an Advanced Stirling Convertor," Ninth International Energy Conversion Engineering Conference (IECEC-2011), San Diego, CA, 2011, AIAA and also published as NASA TM-2012-217292. 